\title{
The Fabrication of Artificial Fine Aggregates Using Stone Sludge and Spent Bleaching Clay
}

\author{
Kangduk Kim ${ }^{\dagger}$ \\ Department of Advanced Materials Engineering, Kyonggi University, Suwon 443-760, Korea \\ (Received July 4, 2014; Revised August 26, 2014; Accepted August 27, 2014)
}

\begin{abstract}
Artificial fine aggregates (denoted AFA) were fabricated using spent bleaching clay (denoted SBC) generated from processed vegetable oil and stone sludge (denoted SS) produced from crushed aggregate manufacturing materials for use as functional construction materials. Each raw material was crushed to particle size finer than $150 \mu \mathrm{m}$, and fine spherical pellets of approximately 1 4 mm in diameter were prepared by a pelletizing process. The physical properties of the AFA were measured with different types of sintering equipment. A new type of vertical furnace that sinters fine aggregates in a fluidized bed at high temperatures was designed and tested. AFA sintered in a rotary kiln at $1125^{\circ} \mathrm{C}$ showed a bulk density of $1.5 \mathrm{~g} / \mathrm{cm}^{3}$ and a water absorption of $16 \%$. AFA sintered in the vertical furnace at $1125^{\circ} \mathrm{C}$ showed a bulk density of $1.9 \mathrm{~g} / \mathrm{cm}^{3}$ and water absorption of $8.5 \%$. The bulk density of the AFA sintered in the vertical furnace showed a bulk density $27 \%$ higher and water absorption $47 \%$ lower than those of AFA sintered in the rotary kiln.
\end{abstract}

Key words : Artificial fine aggregate, Rotary kiln, Vertical furnace, Fluidized bed, Pelletizing

\section{Introduction}

$\mathrm{T}$ he rapid industrialization and urbanization of many countries has increased the generation of industrial and municipal inorganic solid wastes material. In the past, most of this solid waste was sent to landfills, dumped, or incinerated. However, the environmental problems of landfills at overcapacity, as well as dump site pollution and air pollution, have raised the need for alternative disposal methods. Currently, inorganic solid waste is recognized as a resource for applications in various fields, and recycling research focusing on such material is ongoing. Many studies have reported the recycling of industrial waste materials for use as construction materials. ${ }^{1-3)}$

Yip and Tay used incinerated sludge residue to produce lightweight aggregates for concrete, and Blank reported the conversion of red mud from alumina plants into material that could be used in lightweight synthetic aggregates by sintering $\left(1260 \sim 1316^{\circ} \mathrm{C}\right)$. $^{4,5)}$ Bijnen mixed coal fly ash with water and sintered the pelletized mixture at $1200^{\circ} \mathrm{C}$ to produce artificial lightweight aggregates. ${ }^{1)}$ Adell et al. investigated the properties of sintered PFA (Pulverized Fuel Ash) aggregate using conventional and rapid heating rates. ${ }^{6}$ The development of artificial fine aggregates is especially required in many construction fields owing to the absence of local sources of natural sand. ${ }^{7,8)}$

${ }^{\dagger}$ Corresponding author : Kangduk Kim

E-mail : solidwaste@kyonggi.ac.kr

Tel : +82-31-249-1309 Fax : +82-31-244-8241
In this study, artificial fine aggregates were fabricated with spent bleaching clay (SBC) and stone sludge (SS), and a new sintering apparatus for artificial fine aggregates was designed and tested.

\section{Experimental Procedure}

Clay, spent bleaching clay (SBC), and stone sludge (SS) were used as raw materials, all of which were crushed by using a pin milling machine. The clay, SBC, and SS were mixed at a weight ratio of $6: 3: 1$. The mixture was formed into spherical pellets approximately $1 \sim 4 \mathrm{~mm}$ in diameter by a pelletizer. Initially, the formed pellets were dried in a hot-air drying machine at $120^{\circ} \mathrm{C}$ for $48 \mathrm{~h}$, after which they were sintered in an electric muffle furnace at temperatures of 1100,1125 , and $1150^{\circ} \mathrm{C}$ for $10 \mathrm{~min}$. Then, set quantities of the dried AFA pellets were fabricated by sintering in a rotary kiln and in a vertical furnace at $1125^{\circ} \mathrm{C}$ for $10 \mathrm{~min}$. The physical properties of the AFA were measured according to the sintering method used. A flow chart for the AFA fabrication process is shown in Fig. 1.

The idea of a vertical furnace to make AFA was adopted from a fluidized bed system of the type used for the incineration of municipal waste. This type of fluidized bed system can handle fine particles like those of a liquid by means of the "fluidization" of the particles by up-blown gas. ${ }^{9)}$ A photograph of the vertical furnace for sintering is shown in Fig. 2. When the fluidizing bed temperature reached a predetermined temperature, the dried pellets were thrown slowly into the fluidization zone, and the holding time was fixed at 60 min. ${ }^{9)}$ The working conditions of the fluidization zone of 


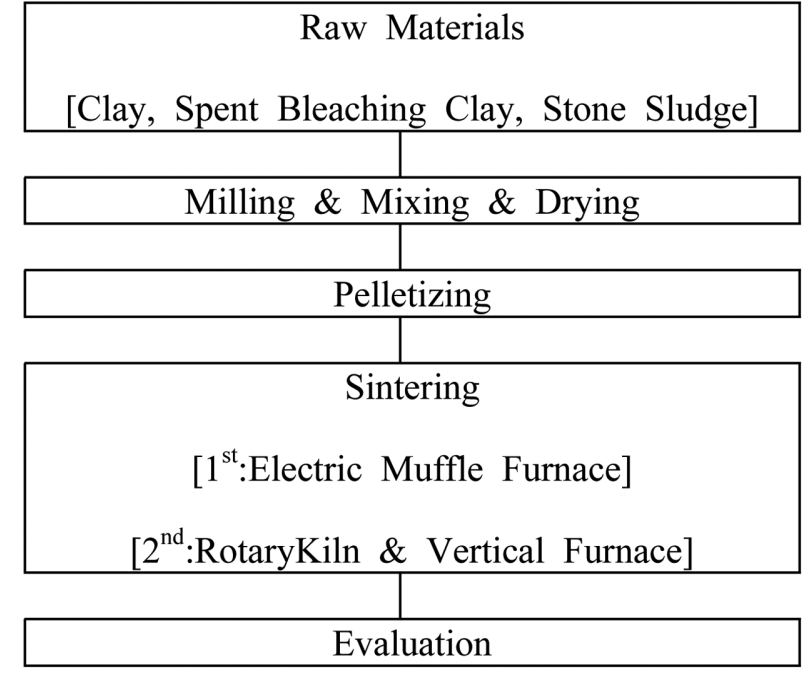

Fig. 1. Flow chart of the artificial fine aggregates fabrication process.

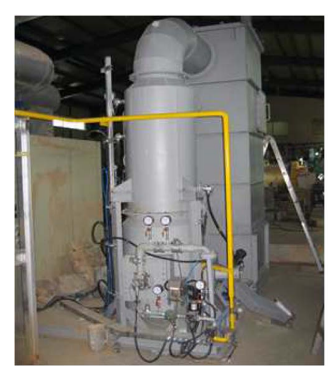

(a)

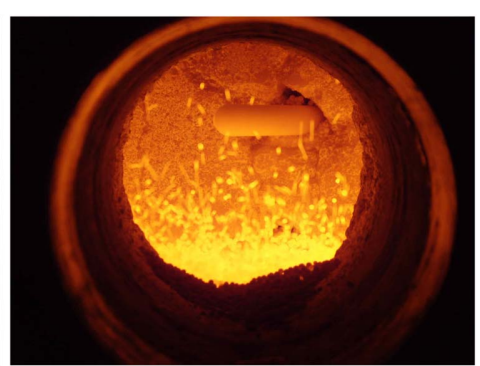

(b)
Fig. 2. Photograph of (a) the vertical furnace and (b) the fluidization zone.

the vertical furnace are shown in Fig. 3. The optimum pressure drop for the uniform fluidization of dried pellets with diameters of $2 \sim 3.35 \mathrm{~mm}$ was $250 \mathrm{mmAq}$ and the fluidization zone was formed ranging from 5 to $8 \mathrm{~cm}$. The temperature gradient of the upper and lower side in the fluidization zone was about $100^{\circ} \mathrm{C}$. The pressure drop increased proportionally with increases in the burner temperature. When the burner temperature exceeded $1320^{\circ} \mathrm{C}$, agglomeration and fusion of the AFA was observed in the fluidization zone

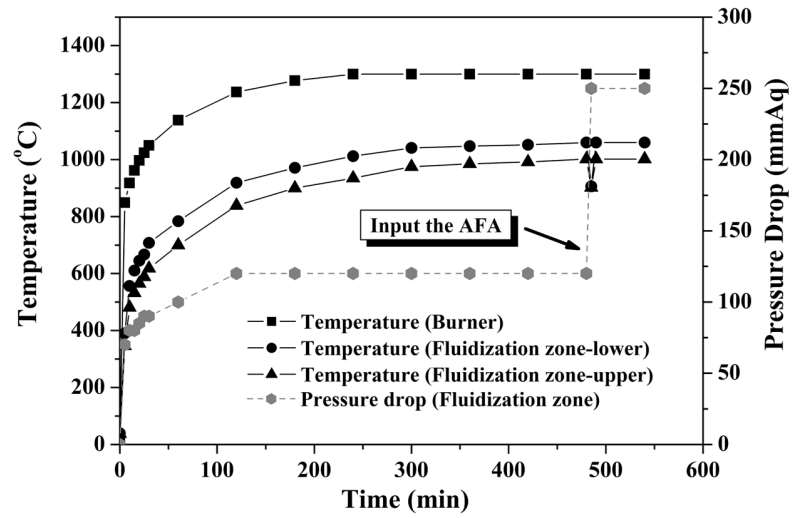

Fig. 3. Working conditions of the fluidization zone in the vertical furnace.

above the gas distributor. At the same time, the pressure drop of the fluidization zone increased rapidly. These phenomena led to the formation of fixed-fusion agglomeration and the destruction of the fluidization zone.

The processing of shale, expanded clay, or slate at high temperatures $\left(900 \sim 1200^{\circ} \mathrm{C}\right)$ in a rotary kiln to produce artificial lightweight aggregates is a process that does not involve a purely chemical reaction but a combination of both physical and chemical reactions. ${ }^{10)} \mathrm{A}$ photograph and a schematic diagram of the rotary kiln used here for AFA sintering are shown in Fig. 4. In this study, a rotary kiln (Takasako Industry CO., LTD., Japan) of pilot-scale (length $=5$ $\mathrm{m}$, inner diameter $=0.3 \mathrm{~m}$ ) was used. This was a short dry kiln without a pre-heater. As shown in Fig. 5, a temperature gradient between the burner part and the feeding part on the inside of the rotary kiln arose and the feeding aggregates were discharged in a section with a set temperature.

The chemical compositions of the raw materials were analyzed by XRF (RINT-8100H/PC, Rigaku, Japan), and the thermal characteristics of these materials were determined by TG/DSC (STA 409 C/CD, Netzsch Co., Germany). The particle size distributions of the pulverized raw materials used for pelletizing were analyzed by laser diffraction (Cilas 1064, CILAS, France). The bulk density and water absorption of the AFA were determined according to the KS F 2503 test method, and the microstructure of the AFA was
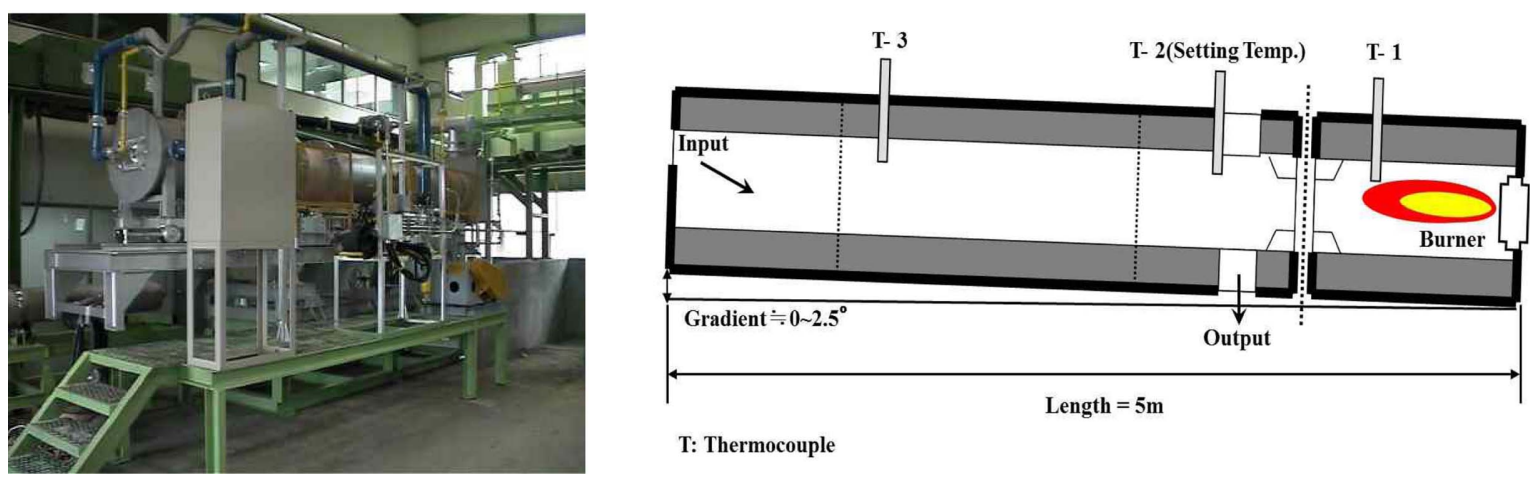

Fig. 4. Photograph and schematic diagrams of the rotary kiln. 


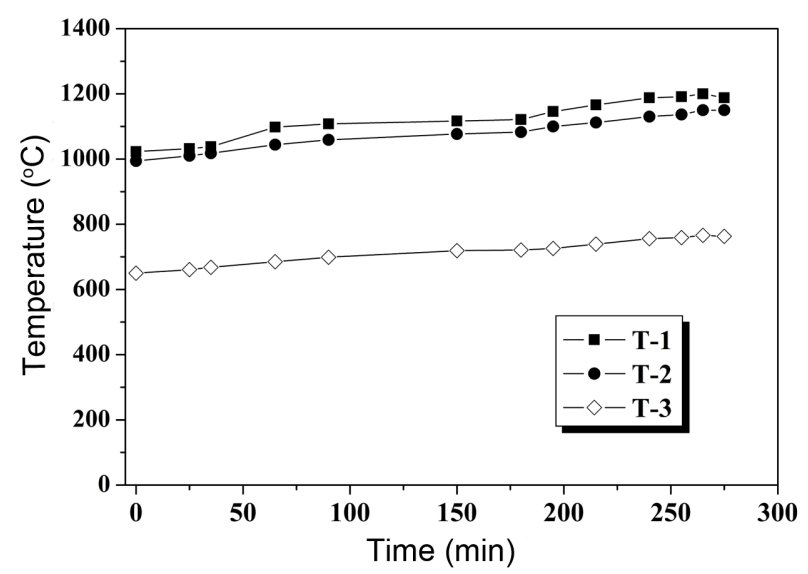

Fig. 5. Temperature gradient of rotary kiln according to the sintering conditions.

observed by means of SEM (JSM-6500F, JEOL, Japan).

\section{Results and Discussion}

The chemical compositions of the raw materials are shown in Table 1. The clay consists of $64.8 \mathrm{wt} \% \mathrm{SiO}_{2}, 17.7 \mathrm{wt} \%$ $\mathrm{Al}_{2} \mathrm{O}_{3}$, and $7.2 \mathrm{wt} \% \mathrm{Fe}_{2} \mathrm{O}_{3}$. The SBC consists of $41.9 \mathrm{wt} \%$ $\mathrm{SiO}_{2}$ and $5.4 \mathrm{wt} \% \mathrm{Al}_{2} \mathrm{O}_{3}$, and shows a high ignition loss of $48.4 \mathrm{wt} \%$. SBC usually contains $20 \sim 40 \mathrm{wt} \%$ of oil by weight because it is mainly produced from the processing of edible oil. ${ }^{11)}$ The SBC used here contained numerous oil components and organic impurities that generated gas via oxidation during the sintering process. The chemical composition of the SS is similar to that of the clay, but the SS had a high concentration of alkali earth metal oxides $(\mathrm{CaO}, \mathrm{MgO})$ and alkali metal oxides $\left(\mathrm{Na}_{2} \mathrm{O}, \mathrm{K}_{2} \mathrm{O}\right)$ than did the clay. The SS contained flux compositions ( $\mathrm{CaO}, \mathrm{MgO}, \mathrm{Na}_{2} \mathrm{O}$, and $\mathrm{K}_{2} \mathrm{O}$ ), which formed melt films on the surface of the AFA at the sintering temperatures used.

The TG/DSC curve of the SBC is shown in Fig. 6. The mass loss of the $\mathrm{SBC}$ in the temperature range of $200 \sim 400^{\circ} \mathrm{C}$ may be mostly due to the evaporation process,

Table 1. Chemical Compositions of the Raw Materials

\begin{tabular}{cccc}
\hline Composition & Clay & $\begin{array}{c}\text { Spent } \\
\text { Bleaching Clay }\end{array}$ & $\begin{array}{c}\text { Stone } \\
\text { Sludge }\end{array}$ \\
\hline $\mathrm{SiO}_{2}$ & 64.8 & 41.9 & 66.7 \\
$\mathrm{Al}_{2} \mathrm{O}_{3}$ & 17.7 & 5.4 & 14.9 \\
$\mathrm{Fe}_{2} \mathrm{O}_{3}$ & 7.2 & 1.7 & 2.3 \\
$\mathrm{CaO}$ & 0.2 & 0.3 & 2.0 \\
$\mathrm{MgO}$ & 0.7 & 0.7 & 1.1 \\
$\mathrm{Na}_{2} \mathrm{O}$ & 0.2 & 0.3 & 3.8 \\
$\mathrm{~K}_{2} \mathrm{O}$ & 1.8 & 0.6 & 5.2 \\
$\mathrm{TiO}_{2}$ & 1.0 & 0.7 & 0.3 \\
$\mathrm{P}_{2} \mathrm{O}_{5}$ & 0.1 & 0.1 & 0.1 \\
$\mathrm{Ig}_{5}$ loss & 6.3 & 48.4 & 3.6 \\
\hline
\end{tabular}

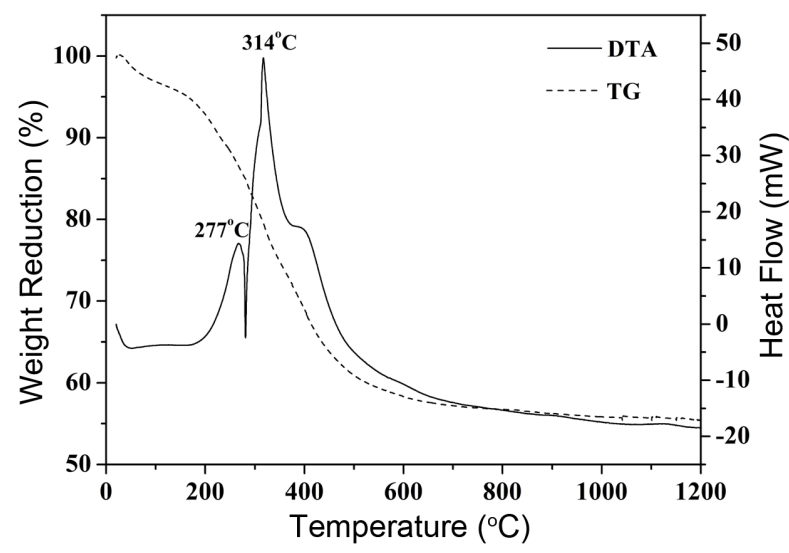

Fig. 6. TG/DSC curve of the SBC.

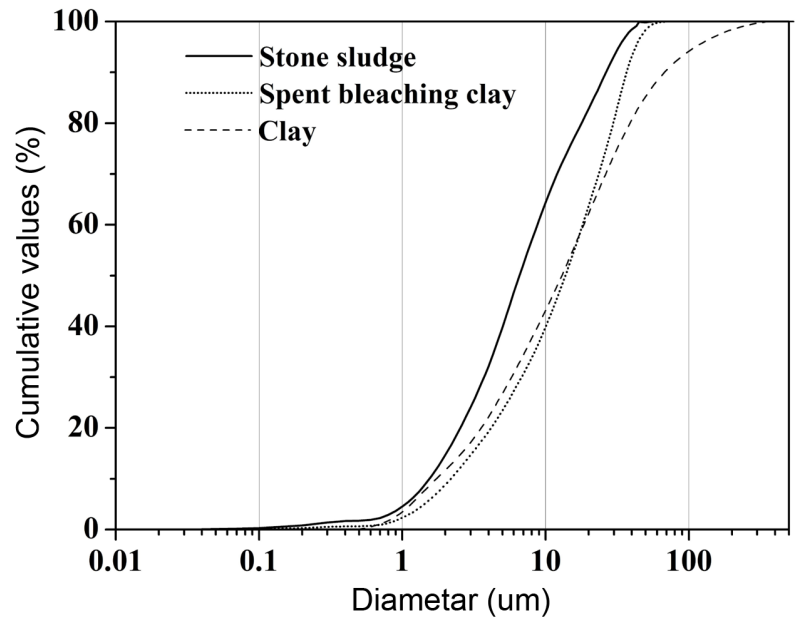

Fig. 7. Particle size distribution of the raw materials.

which is associated with the evolution of volatile products or oils from the SBC. ${ }^{11)}$ The exothermic peak in the temperature range of $300 \sim 400^{\circ} \mathrm{C}$ was due to the carbonization of the residual oils and the combustion of the organic materials.

The particle size distributions of the pulverized raw materials for pelletizing are shown in Fig. 7. The clay had particles with diameters ranging from 0.5 to $300 \mu \mathrm{m}$, with a mean size of approximately $28 \mu \mathrm{m}$. The SBC and the SS had particles with diameters ranging from 0.5 to $70 \mu \mathrm{m}$. The mean particle sizes of the SBC and the SS are $17.1 \mu \mathrm{m}$ and $10.5 \mu \mathrm{m}$, respectively. Bhatty and Tay reported a coarse size limit for pelletizing; a size range coarser than this limit would require an excessive amount of binder to make pellets with feasible dry strength. ${ }^{12,13)}$

The physical properties of the AFA sintered at different sintering temperatures in the electric furnace are shown in Fig. 8. The bulk density of AFA decreased and the water absorption increased with increases in the sintering temperature. The bulk density gradually decreased from 1.35 to $<1 \mathrm{~g} / \mathrm{cm}^{3}$ as the sintering temperature increased from 1100 to $1150^{\circ} \mathrm{C}$. The water absorption gradually increased from 


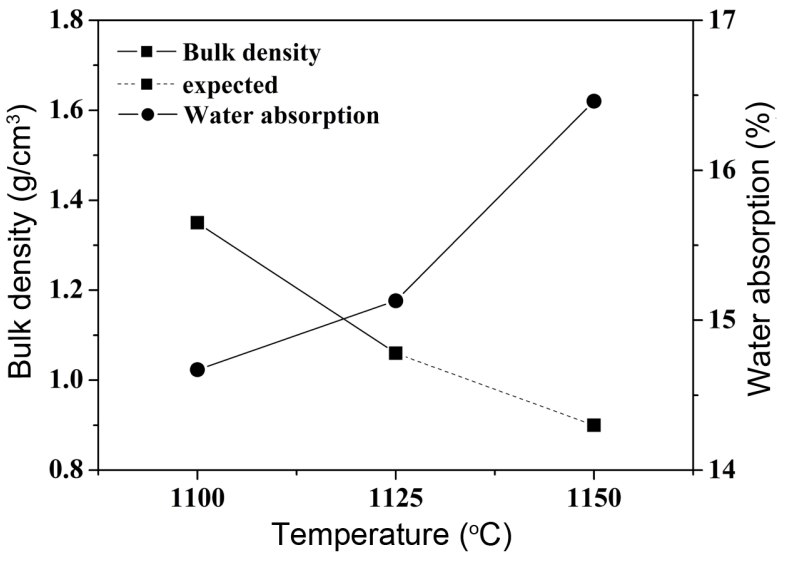

Fig. 8. Physical properties of AFA sintered at different temperatures in an electric furnace.

14.6 to $16.5 \%$ as the sintering temperature increased from 1100 to $1150^{\circ} \mathrm{C}$.

The lightweight of the AFA was due to the composition of the raw materials and the sintering method used. Factors influencing this were as follow: (1) the flux components contained in the SS produced high-temperature glass phases having a high enough viscosity to trap gases, and (2) the oil components contained SBC generated gases at the temperature at which glassy phases formed. ${ }^{14)}$ As a result, all the
AFA showed bulk density values $<1.5 \mathrm{~g} / \mathrm{cm}^{3}$, low enough for their application as artificial fine lightweight aggregates.

The microstructures of the AFA sintered in the electric furnace under various sintering temperatures are shown in Fig. 9. All of the AFA showed structures containing significant numbers of pores. The AFA sintered at 1100, 1125, and $1150^{\circ} \mathrm{C}$ have pores with various sizes between 1 and 100 $\mu \mathrm{m}$. The pore sizes of the AFA increased with increases in the sintering temperature due to the expansion of entrapped gases that formed with the increasing sintering temperature.

The physical properties of the AFA produced using the rotary kiln and the vertical furnace are shown in Fig. 10. The AFA sintered by the rotary kiln at $1125^{\circ} \mathrm{C}$ for $10 \mathrm{~min}$ showed a bulk density of $1.5 \mathrm{~g} / \mathrm{cm}^{3}$ and water absorption of $16 \%$. The AFA sintered by the vertical furnace at $1125^{\circ} \mathrm{C}$ showed a bulk density of $1.9 \mathrm{~g} / \mathrm{cm}^{3}$ and water absorption of $8.5 \%$. The AFA sintered by the rotary kiln showed a bulk density lower and water absorption higher than those of the AFA sintered in the vertical furnace. Kimura et al. reported that the fluidized bed products absorb little water in comparison with the rotary kiln products and that the former show improved fluid ability and workability characteristics for concrete cast with ALA.9)

Figure 11 shows the microstructures of the AFA sintered at $1125^{\circ} \mathrm{C}$ for $10 \mathrm{~min}$ by (a) the rotary kiln and (b) the vertical furnace. The AFA sintered by the rotary kiln had many

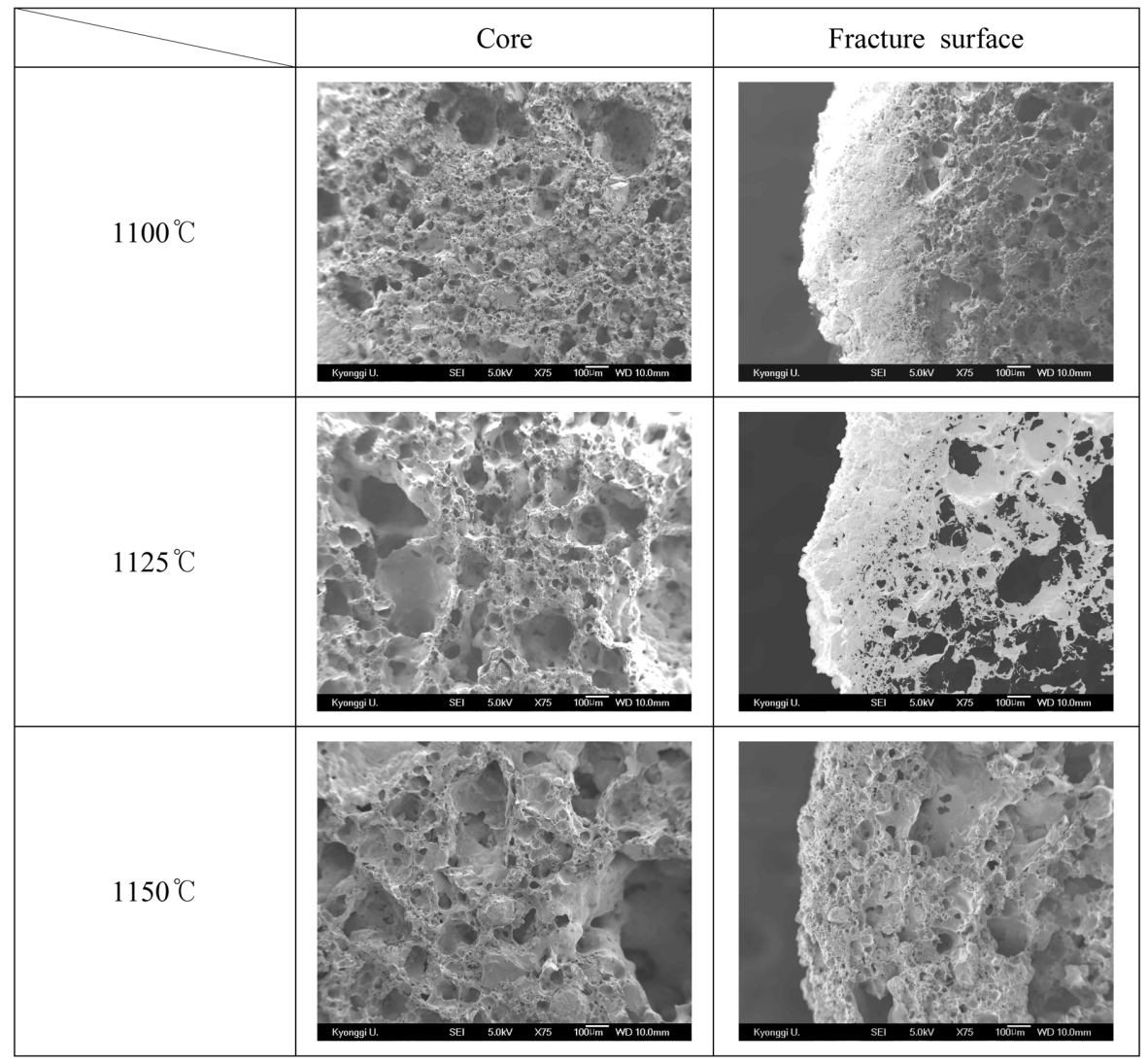

Fig. 9. Microstructures of AFA sintered at various sintering temperatures in an electric furnace. 


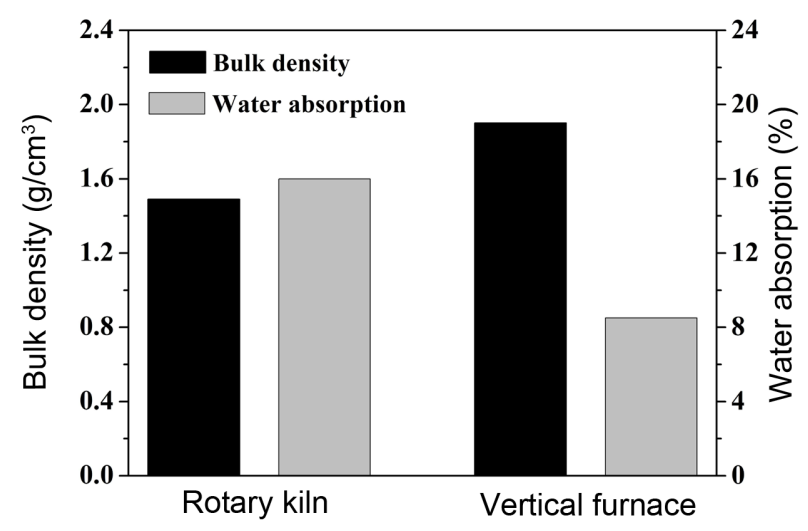

Fig. 10. Physical properties of AFA sintered at $1125^{\circ} \mathrm{C}$ for 10 min in (a) a rotary kiln and (b) a vertical furnace.

micro-pores and a uniform microstructure in general. In contrast, the AFA sintered by the vertical furnace had very large pores on the inside $(>100 \mu \mathrm{m})$ and a dense surface $(<$ $10 \mu \mathrm{m}$ ) on the outside of AFA. The lower water absorption of the AFA sintered by the vertical furnace is most likely related to the formation of the dense shell outside of AFA, as shown in Fig. 11(b). The formation of a dense shell and a porous core, observed in the AFA sintered by various types of furnaces in this study, was considered to be a black coring. The black coring effect was exaggerated by the rapid sintering and by bloating, which may accompany black coring and which was due to the reduction of iron oxide at high temperature. ${ }^{15,16)}$ The aggregates sintered by the rotary kiln and the vertical kiln showed different physical properties due to differences in the input temperatures of the aggregates used in the sintering process. The rapid formation of a glassy film and the densification of the surface of the aggregates by the relatively high input temperature $\left(>800^{\circ} \mathrm{C}\right)$ in the vertical kiln hindered the formation of pores via the sufficient flowing of oxygen into the cores of the aggregates.

\section{Conclusions}

Spherical type AFA was fabricated using pulverized spent bleaching clay and stone sludges. A new type of vertical furnace that can prevent agglomeration between aggregates at sintering temperatures was designed and tested. AFA sintered by a rotary kiln at $1125^{\circ} \mathrm{C}$ showed a bulk density of $1.5 \mathrm{~g} / \mathrm{cm}^{3}$ and water absorption of $16 \%$. AFA sintered at $1125^{\circ} \mathrm{C}$ in a vertical furnace showed a bulk density of $1.9 \mathrm{~g} / \mathrm{cm}^{3}$ and low water absorption of $8.5 \%$. The AFA sintered by the vertical furnace had a dense surface structure and lower water absorption than that of the AFA sintered by the rotary kiln. The aggregates sintered by the rotary kiln and those sintered by the vertical kiln had different physical properties due to differences in the input temperatures of the aggregates used in the sintering process. It is concluded that the newly designed sintering method with the vertical furnace is suitable for making AFA with lower water absorption without agglomeration between the aggregates. In this study, it was possible to manufacture AFA containing SS, SBC, and clay with various levels of bulk density and water absorption by controlling the sintering condition and the kiln type, thus facilitating the application of AFA for use in construction materials in the future.

\section{REFERENCES}

1. J. M. J. M. Bijen, "Manufacturing Processes of Artificial Lightweight Aggregates from Fly Ash," Int. J. Cem. Compos. Lightweight Concr., 8 [3] 191-99 (1986).

2. R. Khanbilvardi and S. Afshari, "Sludge Ash as Fine Aggregates for Concrete Mix," J. Environ. Eng., 121 [9] 633-38 (1995).

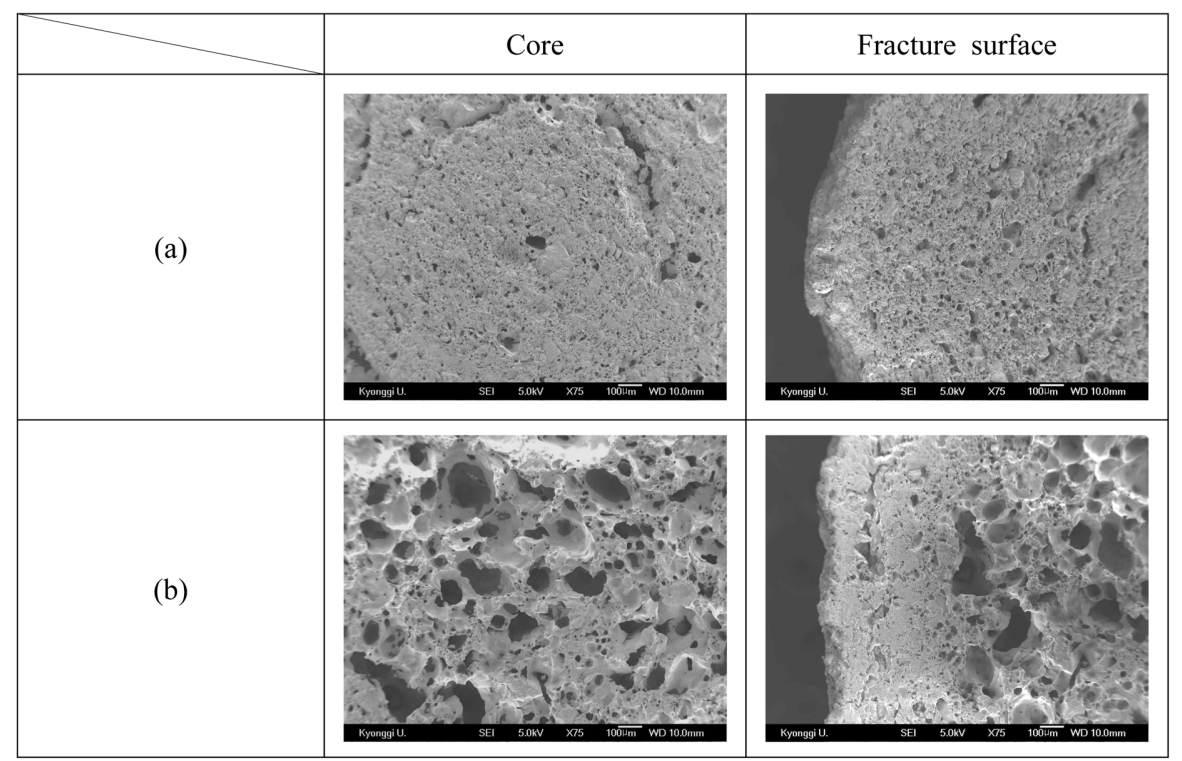

Fig. 11. Microstructures of AFA sintered at $1125^{\circ} \mathrm{C}$ for $10 \mathrm{~min}$ in (a) a rotary kiln and (b) a vertical furnace. 
3. J. H. Tay, K. Y. Show, and S. Y. Hong, "Concrete Aggregates Made from Sludge-marine Clay Mixes,” J. Mater. Civ. Eng., 14 [5] 392-98 (2002).

4. W. K. Yip and J. H. Tay, "Aggregates Made from Incinerated Sludge Residue," J. Mater. Civ. Eng., 2 [2] 84-93 (1990).

5. H. R. Blank, "Red Mud from Alumina Plants as a Possible Source of Synthetic Aggregates;" J. Test. Eval., 4 [5] 355-58 (1976).

6. V. Adell, C. R. Cheeseman, A. Doel, A. Beattie, and A. R. Boccaccini, "Comparison of Rapid and Slow Sintered Pulverised Fuel Ash," Fuel, 87 187-95 (2008).

7. J. M. Khatib, "Properties of Concrete Incorporating Fine Recycled Aggregate," Cem. Concr. Res., 357 63-69 (2005).

8. J. P. Goncalves, L. M. Tavares, R. D. Toledo Filho, E. M. R. Fairbairn, and E. R. Cunha, "Comparison of Natural and Manufactured Fine Aggregates in Cement Mortars," Cem. Concr. Res., 37 924-32 (2007).

9. S. Kimura, K. Kimura, H. Kamiya, and M. Horio, "A Novel Fluidized Bed Process to Produce Fine-grade Artificial
Lightweight Aggregate," Powder Technol., 146 111-20 (2004).

10. A. A. Boateng, Rotary Kiln; pp. 285-86, ButterworthHeinemann, Oxford, 2008.

11. W. T. Tsai, H. P. Chen, M. F. Heish, H. F. Sun, and S. F. Chien, "Regeneration of Spent Bleaching Earth by Pyrolysis in a Rotary Furnace," J. Anal. Appl. Pyrolysis, 63 15770 (2002).

12. J. I. Bhatty, A. Malisci, I. Iwasaki, and K. J. Reid, "Sludge Ash Pellets as Coarse Aggregates in Concrete," Cem. Concr. Aggregate, 14 [1] 55-61 (1992).

13. J. H. Tay, S. Y. Hong, and K. Y. Show, "Reuse of Industrial Sludge as Pelletized Aggregate for Concrete," J. Environ. Eng., 126 [3] 279-87 (2000).

14. C. M. Riley, "Relation of Chemical Properties to the Bloating of Clay," J. Am. Ceram. Soc., 34 [4] 121-28 (1951).

15. W. E. Brownell, "Black Coring in Structural Clay Products,” J. Am. Ceram. Soc., 40 [6] 179-87 (1957).

16. P. S. Nichoson and W. A. Ross, "Kinetics of Oxidation of Natural Organic Material in Clay," J. Am. Ceram. Soc., 53 [3] 154-58 (1970). 